\title{
FENÔMENOS GEOGRÁFICOS ORIGINADOS PELAS ERBS DA TELEFONIA CELULAR
}

\author{
geographical phenomena originated by the BTS of cellular telephone
}

\author{
Maurício José Kaczmarech*
}

\begin{abstract}
Resumo
Durante a pesquisa, que buscou indicar qual era a influência da infraestrutura da telefonia celular sobre a paisagem urbana, foi constatada a ocorrência de alguns fenômenos geográficos gerados pela presença das Estações Rádio Base (ERBs) da telefonia celular. Foram classificados os fenômenos geográficos da concentração, alinhamento visual, compartilhamento, sobreposição e bordeamento. A altura das torres, o local de instalação, a topografia da cidade, o crescimento vertical, a posição das vias de maior trânsito, as orientações legais e os acordos para a instalação de ERBs, influem na classe de fenômenos que ocorrem. Cada fenômeno evita ou adiciona novos detalhes na paisagem urbana, agindo na sensação que o observador tem ao visualizar a cidade, sendo o resultado mais comum, a poluição visual. O fenômeno da concentração de ERBs, a sobreposição destas sobre estruturas já existentes e o alinhamento, incluem novas feições à cidade. Já o fenômeno do compartilhamento evita a instalação de novas torres e o da sobreposição, reduz a influência visual de ERBs junto à paisagem. O estudo foi realizado na cidade de Ponta Grossa e serve de referência para outras cidades, que também possuem ERBs de telefonia celular, ou seja, a maioria delas.
\end{abstract}

Palavras-chaves: Telefonia celular, paisagem urbana, fenômenos geográficos.

\begin{abstract}
During a research that indicate what was the influence of the cellular infrastructure on the urban landscape, has been found the occurrence of certain geographic phenomena generated by the presence of Base Transceiver Station (BTS) of mobile telephones. We classified the phenomena of geographic concentration, visual alignment, sharing, overlapping and bordering. The height of the towers, their location, the city's topography, the vertical growth, position of the largest transit routes, guidelines and legal agreements for the installation of base stations affect the class of phenomena that occur. Each phenomenon prevents or adds new details in the urban landscape, acting in the sense that the observer has to observe the city, being the most common result, the visual pollution. The phenomenon of concentration of base stations, the overlap of these structures on existing alignment and includes new features to the city. The phenomenon of sharing prevents the installation of new towers. And the overlap reduces the visual impact of base stations along the landscape. The study was conducted in the city of Ponta Grossa and serves as a reference for other cities that also have cellular base stations, ie, most of them.
\end{abstract}

Key words: Cellular telephony, urban landscape, geographic phenomena.

\section{Resumen}

Durante una investigación que indique cuál fue la influencia de la infraestructura celular en el paisaje urbano, se ha encontrado la aparición de ciertos fenómenos geográficos generados por la presencia de estaciones base (RBS) de los teléfonos móviles. Se clasificó a los fenómenos de concentración geográfica, la alineación visual, el compartir, la superposición y bordeamento. La altura de las torres, la ubicación de instalación, la topografía de la ciudad, el crecimiento vertical, la posición de las principales rutas de tránsito de las directrices y acuerdos legales para la instalación de estaciones base de afectar a la clase de fenómenos que se producen. Cada fenómeno se eviten o se agrega nuevos detalles en el paisaje urbano, actuando en el sentido de que el observador tiene que observar la ciudad, siendo el resultado más común, la contaminación visual. El fenómeno de la concentración de estaciones de base, la superposición de estas estructuras en alineación existente e incluye nuevas características para la ciudad. El fenómeno de compartir impide la instalación de nuevas torres. Y la coincidencia reduce el impacto visual de las estaciones base a lo largo del paisaje. El estudio se realizó en la ciudad de Ponta Grossa y sirve como referencia para otras ciudades que también dispone de estaciones base celulares, es decir, la mayoría de ellos.

Palabras-Claves: Telefonía celular, paisage urbano. fenómenos geográficos.

(*) Mestrando do Programa de Pós-Graduação em Geografia da Universidade Estadual de Ponta Grossa - Campus de Uvaranas - Av. Carlos Cavalcanti 4748, Bloco CIPP, CEP: 84030-900 - Ponta Grossa (PR) - Brasil, Tel.(+ 55 42) 3028.7571 - mauricio. jk@hotmail.com 


\section{INTRODUÇÃO}

Antes de tudo, vale lembrar que as redes de telecomunicações implantadas sobre as cidades (temporalmente listando-as: rádio, televisão, telefonia fixa à cabo, telefonia fixa à distância, telefonia celular e internet sem fio), foram inserindo na paisagem urbana novas feições, o que pode ser notado a um simples olhar (exemplo, na figura 01).

A implantação de sistemas de telefonia celular nas cidades resultou na inclusão de novos elementos, as chamadas Estações Rádio Base (ERBs). Estas são distribuídas segundo ditames técnicos limitados pela extensão do território a ser criado (de oferta de serviço de telefonia), pelo relevo da região e pelo crescimento vertical (presença de edifícios e outras construções que funcionam como barreiras às emissões das ERBs). Cada Estação Rádio Base é um ponto de uma rede de telecomunicações, onde cada ponto se conecta a outro, sejam eles da infraestrutura (as ERBs), ou como os representados pelos usuários (telefones móveis, os celulares).

\section{A PAISAGEM URBANA}

Fazendo parte do vasto fenômeno representado pela evolução da paisagem urbana que transcorre, prioritariamente, pela influência do desenvolvimento econômico e social, podem-se identificar modificações dependentes de inovações tecnológicas e novas aplicações de tecnologias pré-existentes. Essas alterações da paisagem trazem perceptíveis modificações que se impõem ao observador. Uma paisagem com novas características, conformações e estilos, consequentemente, introduz experiências sensoriais anteriormente ausentes, transmitindo novos significados que alteram a percepção da cidade e geram influências, positivas ou negativas. Um caso clássico e merecedor de grande atenção é o da poluição visual.

Atualmente, não é a arquitetura dos edifícios ou a infraestrutura de iluminação pública, transporte, etc., que vem impondo novas características sobre as cidades, mas sim, os sistemas de comunicação, que estão ao alcance de grande parte da população. Nas últimas décadas, foram implantadas novas tecnologias ou novas formas de utilizar conhecimentos antigos, modificando o ambiente urbano. Uma dessas novas características é a presença das ERBs da telefonia celular, as quais são facilmente encontradas na paisagem urbana por, na maioria dos casos, apresentar uma torre com dezenas de metros que sustenta as antenas de recepção e retransmissão da estação.

Entretanto, quando se analisa o conceito de paisagem deve-se considerar alguns fatores como a história e a evolução da sociedade, como bem lembra Santos (1986), indicando que a paisagem urbana é composta por diferentes centros (de negócios, de moradia, lazer, implantação de indústrias, etc.), sendo característica comum na composição da paisagem, a participação de objetos naturais, objetos produzidos pelo homem e os objetos sociais. Esta composição é indicada como algo dinâmico, em constante modificação, comandada pelas mudanças sociais e políticas e, dentre estas, as modificações que buscam adaptar a cidade às novas necessidades da sociedade.

Santos (1986) ensina ainda que, a paisagem representa um determinado momento do desenvolvimento da sociedade, e não apenas uma simples acumulação de mudanças anteriores, citando que a paisagem assim como o espaço, modifica-se para acompanhar as transformações da sociedade. As formas são modificadas, renovadas ou suprimidas para atender as transformações sociais. $\mathrm{O}$ autor lembra uma frase do filósofo e geógrafo Kant: "A história é um processo sem fim, mas os objetos mudam e dão uma geografia diferente a cada momento da história". Hoje sobre as cidades há a expansão da telefonia, a qual já tem milhões de usuários somente no Brasil.

As características da paisagem urbana, dentre as quais se identifica o crescimento vertical (elevação da altura das edificações com relação a sua velocidade de instalação) e a caracterização (feições dos edifícios e outras construções), tem como impulsores, além das necessidades da população, as intenções das empresas, dos governos e as possibilidades oferecidas pela tecnologia disponível no momento. Esta última delimita as possibilidades de construção e de aplicação de 
investimentos, de busca de lucro e, consequentemente, de alteração das feições da paisagem urbana.

Não se pode perder de vista as delimitações e orientações legais que normatizam a instalação de novos objetos urbanos sobre a cidade. Neste momento, vale lembrar a questão da saúde pública como sendo o principal impulsor das regulamentações na área da telefonia celular, devendo ser examinada, pois é o fator que movimenta associações de moradores, OSCIPs e políticos, em direção do controle da expansão da infraestrutura das telecomunicações dentro das cidades.

A morfologia da paisagem urbana é resultado de uma torrente de elementos formadores com origens e intensidades diferentes, podendo ou não existir relações entre eles. Há os elementos físicos que tomam parte na modelagem da paisagem urbana (topografia, cursos d'agua, tipos de solo, etc.) e os elementos sociais (orientação econômica da cidade, número de habitantes, etc.). Destaca-se ainda, a evolução tecnológica com aplicações sociais e comerciais, refletindo sobre a modelação da paisagem urbana. Na lista de detalhes de uma cidade podem-se citar casas, edifícios, pontos comerciais, elementos de comunicação visual, sistemas de telecomunicações, sistema de distribuição de energia, etc., como importantes elementos compositores da paisagem influenciados pela tecnologia.

Nesse sentido deve-se dizer que existem várias origens para esses elementos, tais como a institucional (oriundas do planejamento administrativo público), da atividade privada (orientadas pela busca de capital), ou simplesmente do povo em sua vida cotidiana (que busca suprir somente as necessidades básicas). Assim, a cidade e a paisagem urbana sofrem um processo contínuo de evolução orientado não só pelas necessidades da população, mas também, pelas intenções de empresas particulares e órgãos do governo. As inovações tecnológicas disponíveis utilizadas por esses três grupos ajudam a criar um novo modelo para a paisagem das cidades.

Desta maneira, vale ratificar que o estudo da participação das inovações tecnológicas no processo de alteração urbana é de fundamental importância, já que o Homem vive em um mundo onde ciência e tecnologia são ferramentas primordiais em todas as atividades humanas.

\section{PAISAGEM URBANA E O MEIO-TÉCNICO-CIENTÍFICO-INFORMACIONAL}

A paisagem é definida por Santos (1988), como tudo o que se pode observar, ou seja, o que a visão alcança. Concebida no domínio do visível, não é formada exclusivamente de volumes, mas de cores, movimentos, etc.. Conjugada com o espaço resulta em movimentos superficiais e de fundo da sociedade com funcionalidade unitária, um mosaico de relações, de formas, funções e sentidos. A paisagem é o sentido da materialidade e constitui a fonte das relações sociais. O autor contempla o conceito de meio-técnico-científico-informacional, indicando a necessidade de observar a forma, a função, estrutura e processos, os fixos e fluxos, os sistemas e redes formadas por objetos urbanos e o seu sistema de ações.

Nas últimas décadas do século XX, inúmeras inovações tecnológicas foram introduzidas nos vários setores das atividades humanas, sendo que muitas destas possuem reflexos sobre a evolução do modelo da paisagem urbana. Pode-se encontrar um elo entre esta paisagem e as inovações tecnológicas com facilidade. Em alguns casos, rápidas introduções de novos objetos no meio urbano em resposta a uma demanda social crescente como, por exemplo, o sistema de telefonia celular, provoca, além de alterações em âmbito social e profissional, a introdução de novos elementos componentes na construção da paisagem das cidades.

\section{A FORMA SEGUE A FUNÇÃO}

Vários recursos tecnológicos vêm introduzindo novas feições à morfologia urbana, acompanhadas de novas relações sociais e econômicas. Esses elementos até a poucas décadas atrás, não se perfilavam no grupo dos classificados como objetos urbanos. Esses novos elementos modeladores produzem uma díspar orientação para a evolução do traçado das feições urbanas, seja pelo uso do solo, pelo crescimento vertical ou pelas relações que as várias regiões de uma cidade possuem. 
Existe grande importância da tecnologia na atual composição da paisagem urbana como lembra Castro (1995), citando uma observação de Haesbaert onde é indicado que a forma segue a função, algo que foi difundido pela arquitetura modernista norte-americana do início do século passado. Para apoiar esta afirmação, encontram-se muitas ocorrências próprias da paisagem urbana moderna. A orientação instrumental-funcionalista está presente de forma prolífera na cidade atual, podendo citar, como exemplo, uma torre para telefonia celular que é pura funcionalidade, não há arte, não há estilo, há somente a forma que é orientada por sua função. Basta comparar uma torre de televisão ou telefonia móvel com a torre Eiffel, nota-se a falta de estilo e estética, somente a funcionalidade aparece na torre de telefonia.

Vilagrasa (1991) diz que o estudo da forma urbana, processos e pessoas que a modelam, é a base para um estudo sobre a morfologia urbana. Cumpre observar ainda que as novas tecnologias aplicadas interferem nos processos sociais e na vida das pessoas. Neste ponto, encontra-se o elo entre a temática das aplicações tecnológicas, o social e a composição da morfologia da paisagem urbana.

\section{MODIFICAÇÃO DA PAISAGEM URBANA}

Entendendo o termo paisagem urbana como sendo "a configuração visual resultante da contínua e dinâmica interação entre os elementos naturais, os edificados ou criados e o próprio homem, que reflete a dimensão cultural de uma comunidade" (Anteprojeto de Lei do Mobiliário Urbano de Ribeirão Preto, 1999), pode-se afirmar que "o grau de excelência das suas características visuais", é um forte elemento que define a qualidade desta paisagem urbana. Da mesma maneira, conclui-se que poluição visual "é o efeito danoso que determinadas ações antrópicas e/ou naturais produzem nos elementos de uma paisagem, acarretando um impacto negativo na sua qualidade" (Anteprojeto de Lei do Mobiliário Urbano de Ribeirão Preto, 1999).

A implantação de antenas e torres para as comunicações vem infligindo formas estranhas sobre a paisagem urbana, chegando a desvirtuar os elementos sobre ou próximo aos quais são instalados. Até mesmo novas normas foram criadas para limitar os impactos negativos que as instalações de telecomunicações inserem na paisagem urbana. Tal fenômeno urbano tem suas implicações sobre a paisagem. Vários estudiosos indicam que certos detalhes de uma cidade, tanto podem trazer beleza quanto poluição visual. Preciosa é a contribuição de MAS (2002), que em seu trabalho de mestrado apresenta simulações sobre a influência dos elementos técnicos que compõem os sistemas urbanos, neste caso, os objetos da telefonia fixa e a distribuição da energia elétrica.

Quanto às causas e leis de articulação e transformação do espaço geográfico enquanto espaço social, as tecnologias são elementos de criação para novas tendências sociais, bem como transformações, não só do aspecto morfológico da paisagem urbana, mas também de suas atividades sociais. Quanto à transformação gerada pela tecnologia responsável em parte pela modelação urbana, podem-se encontrar indicações de Sanchez (1991) e Santos (2001), onde citam que o espaço em transformação deve ser observado em suas raízes e em suas motivações, que brotam de instâncias econômicas, político-institucionais e ideológico-culturais, que articulam os processos sociais e dão orientação até mesmo na aplicação de tecnologia no meio urbano.

A oferta de novas tecnologias é, economicamente, um grande negócio, da mesma forma que já é parte da cultura moderna e do modo de vida atual. Não se pode imaginar o mundo moderno, por exemplo, sem as construções pré-moldadas que se adaptam às exigências de economia e rapidez de construção, tão comuns e necessárias para a rápida expansão em muitas cidades.

A importância da tecnologia na caracterização da paisagem urbana é indiscutível. Como indicam as afirmações de Carlos (1994), a paisagem é humana, possuindo uma dimensão histórica e social reproduzida pela vida do homem. A paisagem, ainda segundo a autora, não é somente a expressão do trabalho social materializado, mas também a expressão de um modo de vida. É fácil dar exemplos de tecnologias que ditam o atual modo de vida, possuindo relações que criam as formas e as funções a serem cumpridas. 
Nessa linha de estudo, Castro (1995) afirma que não é possível dissociar forma e função da análise do espaço, sendo necessário ir além, inserindo forma e função na estrutura social para captar a natureza histórica do espaço. A estrutura diz respeito à natureza social e econômica de uma sociedade em um dado momento do tempo, sendo a matriz social onde as formas e funções são criadas e justificadas. Tais ligações, no caso das tecnologias em relação a uma paisagem urbana, são simples. Isto porque, as necessidades sociais de interação com o valor e uso do solo para atingir seus objetivos, buscam apoio nas novas tecnologias e aplicações, sendo ferramentas utilizadas pela sociedade para dar meios de concretização para os novos passos da evolução urbana. Como resultado final, entre outros, surgem novas características para o modelo das feições da paisagem urbana.

Para Vilagrasa (1991), a paisagem deve ser examinada de vários ângulos, onde as edificações e a imagem urbana devem se entrecruzar com a percepção da imagem do urbano em uma paisagem global. Mopu (1987) lembra que existe uma variedade morfológica de elementos que fazem parte da paisagem organizada que é uma cidade, podendo ser detalhes pontuais, lineares ou superficiais. Os novos elementos introduzidos na paisagem devem ser analisados para que um conceito profundo possa ser encontrado.

Santos (2003), afirma que o meio geográfico, ao longo da história da humanidade, é construído pela ação do Homem. Essa construção depende da relação humana com a natureza, mas também com o fenômeno da "tecnificação" do meio geográfico, ou seja, o espaço de vivência do Homem atual está permeado por objetos técnicos, muitos dos quais da área das telecomunicações, como é o caso da telefonia celular, formando o que o autor chama de "meio-técnico-científico-informacional". A instalação de elementos da infraestrutura da telefonia celular modifica a dinâmica espacial do território com a implantação de novos elementos na paisagem, como também de novas condições ambientais, ou seja, radiações que são emitidas sobre a cidade.

\section{ERBs: tipos e caracterizações}

Convém ressaltar que para qualquer levantamento de dados referente à telefonia celular, deve considerar que existem dois tipos de Estações Rádio Base (ERBs) quanto a sua forma de instalação (figura 1), sendo elas:

- De solo - quando um terreno é preparado para ser utilizado especialmente para a instalação de uma ERB. Neste caso, é instalada sobre o solo uma torre na qual são fixadas as antenas de comunicação. O instrumental eletrônico, sistema de aclimatização, etc., ficam instalados no solo dentro de um compartimento, um container;

- De topo de telhado - na verdade são instaladas sobre a laje ou sobre a caixa de água de edifícios. Existe uma minúscula torre, que na verdade é somente um suporte para as antenas, não possuindo a função de elevar essas antenas em relação ao solo.

\section{FENÔMENOS GEOGRÁFICOS E AS ERBS}

A constante ampliação do número de usuários da telefonia móvel celular demanda o incremento da infraestrutura necessária para manter o sistema em pleno funcionamento. $\mathrm{O}$ atendimento desta demanda crescente depende do planejamento da ampliação das redes de telefonia de cada empresa do setor de oferta de conexões de celular, bem como das possibilidades oferecidas pela cidade (topografia, crescimento vertical, distribuição da população pela cidade, principais vias de fluxo, etc.), e dos limites e obrigações impostas pelas legislações vigentes. Todas estas características atuam sobre o número de ERBs existentes, criando pontos de atração e repulsão de estações, implantando na paisagem urbana objetos que trazem novas sensações, mesmo que somente como fenômeno de perspectiva. 
Os fenômenos sociais ligados ao da telefonia celular são variados. Por exemplo, Tofeti (2007), conclui que a telefonia celular é parte indissolúvel do atual modo de vida e verdadeira revolução social ao permitir o acesso a modernos meios de comunicação às classes de menor renda. $\mathrm{O}$ autor lembra que a popularização de outras "Tecnologias da Informação" encontra na telefonia celular um meio de disseminação (internet, televisão e rádio já são instalados dentro do corpo dos atuais aparelhos de telefone celular pessoal), dando mobilidade às pessoas e a suas atividades, implementando a evolução nas espacializações e na dinâmica da produção espacial.
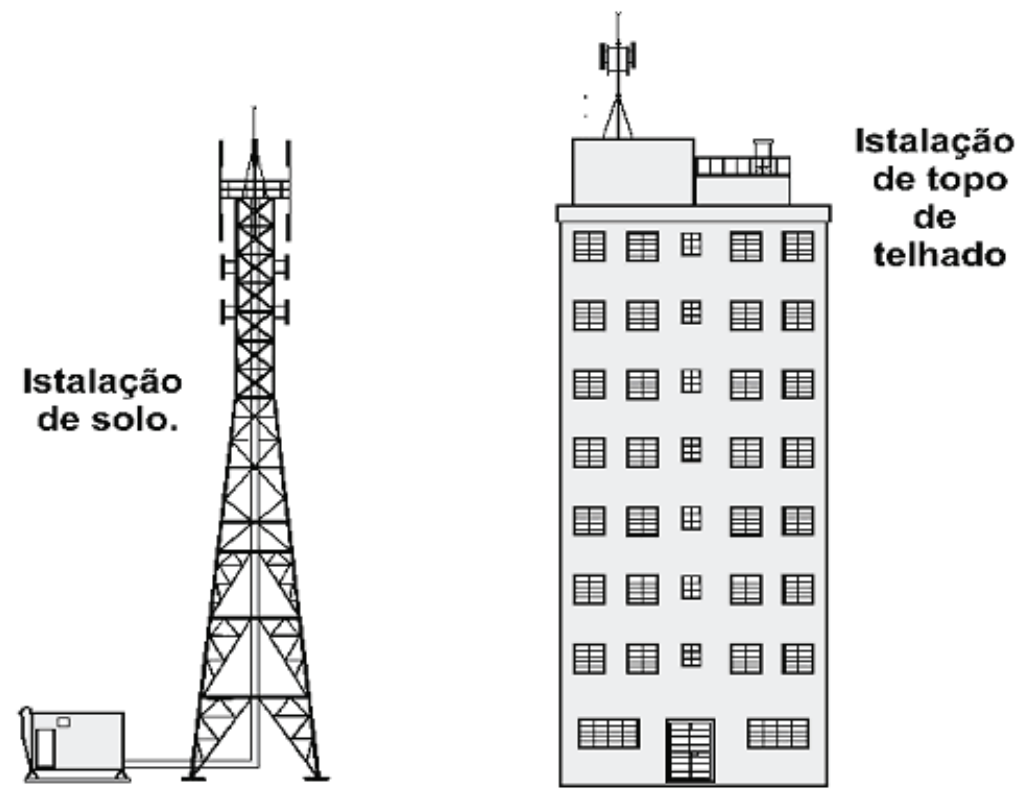

Figura 1 - Os dois tipos de ERBs: a de solo e a de laje ou topo de telhado

Harvey (2005) indica que existe uma perda de simbolismo da paisagem urbana, devido à prática do zoneamento funcional (com a criação de áreas comerciais, residenciais, industriais, etc.). No caso da telefonia, o zoneamento carrega consigo características que influenciam na criação de redes de telefonia. A zona industrial fica afastada do centro da cidade. As principais vias de trânsito atraem as ERBs para o centro da cidade por ter um crescimento vertical mais acentuado, sendo o local de maior obstrução das ondas emitidas pelas mesmas. Na telefonia, cada zona da cidade oferece características técnicas diferentes, e as ERBs são instaladas em cada uma de modo distinto, acrescentando um simbolismo técnico especial ao já existente.

$\mathrm{O}$ autor também indica que em função das mudanças tecnológicas, formas urbanas dispersas, descentralizadas e desconcentradas, são mais facilmente executáveis do que há décadas atrás. Entretanto, no caso da infraestrutura da telefonia, esses padrões não são obedecidos, pois se notam claramente padrões de concentração e de alinhamento. A criação de uma rede de telefonia móvel ignora o zoneamento feito pelos administradores das cidades, não diferenciando a zona central, periférica e de habitação por suas funções, mas tão somente observando o volume de fluxos de usuários em movimento, adaptando-se a concentração e fluxos da população, que são variáveis. Isto porque existe o movimento dos usuários entre as áreas de habitação, de comércio, industrial e vias principais de trânsito, que conduzem os fluxos de usuários dentro e para fora das cidades.

Quando da execução da pesquisa intitulada "Redes técnicas: o caso da infraestrutura da telefonia móvel em Ponta Grossa - PR" (KACZMARECH, 2009), foram identificados alguns fenômenos paisagísticos interessantes (que dependem da observação): físico-urbanos, de posição (que dependem do posicionamento geográfico das ERBs) e de utilização (quando ocorrem usos diversos das infraestruturas). Assim, durante o desenvolvimento desta pesquisa, foram observados fenômenos, alguns de natureza normativa (devido às leis que controlam a instalação de ERBs), outros gerados por ditames de natureza técnica (a busca de melhores pontos para formar as redes 
de telefonia na cidade) e os que são fenômenos visuais (os que resultam dos dois primeiros e criam fenômenos visuais observáveis). Cada fenômeno recebeu uma denominção, sendo elas:

- Concentração;

- Alinhamento visual;

- Compartilhamento;

- Sobreposição;

- Bordeamento.

Cada um desses fenômenos tem uma razão de ser, seja por ditames técnicos (emissões de ondas com potência determinada que viajem somente em linha reta), da Geografia (física ou humana), do local ou por limitações da própria da telefonia celular legislação (que indica locais onde não se pode instalar ERBs). O estudo desses fenômenos é primordial quando se quer pensar tecnicamente a legislação de uso do solo envolvendo a telefonia celular, bem como quando se busca os reflexos da presença das ERBs sobre como é sentida a cidade por seus habitantes.

\section{FENÔMENO DA CONCENTRAÇÃO}

Ocorre quando uma determinada área mostra-se a mais indicada para a instalação de pontos de uma rede de telefonia móvel. Esse poder de atração pode induzir uma ou mais empresas de telefonia móvel a que instalarem suas ERBs naquela posição. Este tipo de fenômeno chega a colocar duas ou mais torres próximas umas das outras.

Assim, num raio de centenas, ou mesmo dezenas de metros, podem se posicionar várias torres de ERBs (muitas vezes, participam deste fenômeno, não só as torres de telefonia móvel, mas também outras, como de telefonia fixa). As torres, com esse fenômeno são avistadas na paisagem, estando umas próximas das outras. Isto tanto a longa distância (como na figura 2) quanto a curta distância (figura 3), sempre destacando sua concentração.

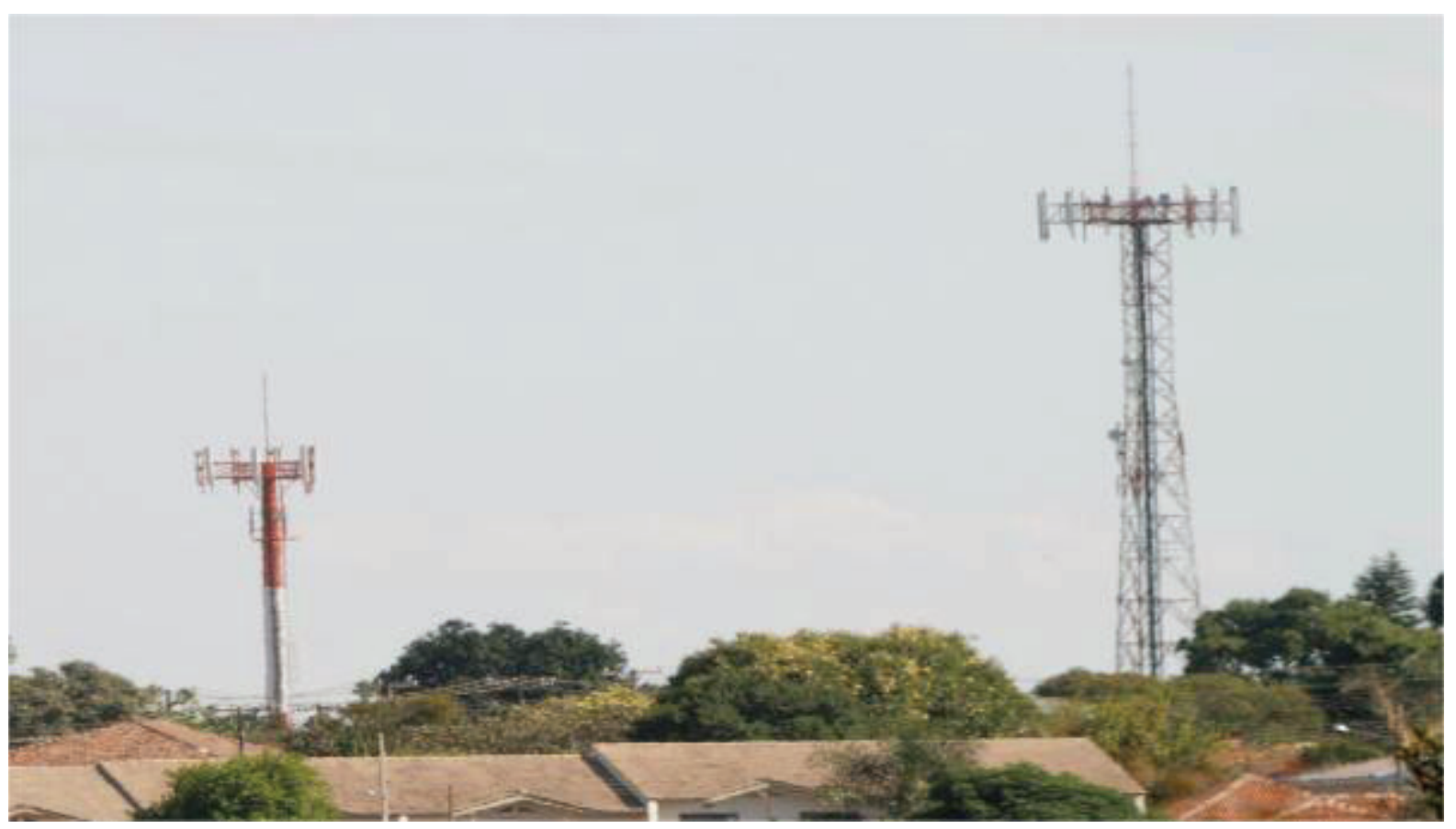

Figura 2 - Fenômeno da concentração com três ERBs, fixadas em uma mesma área. 


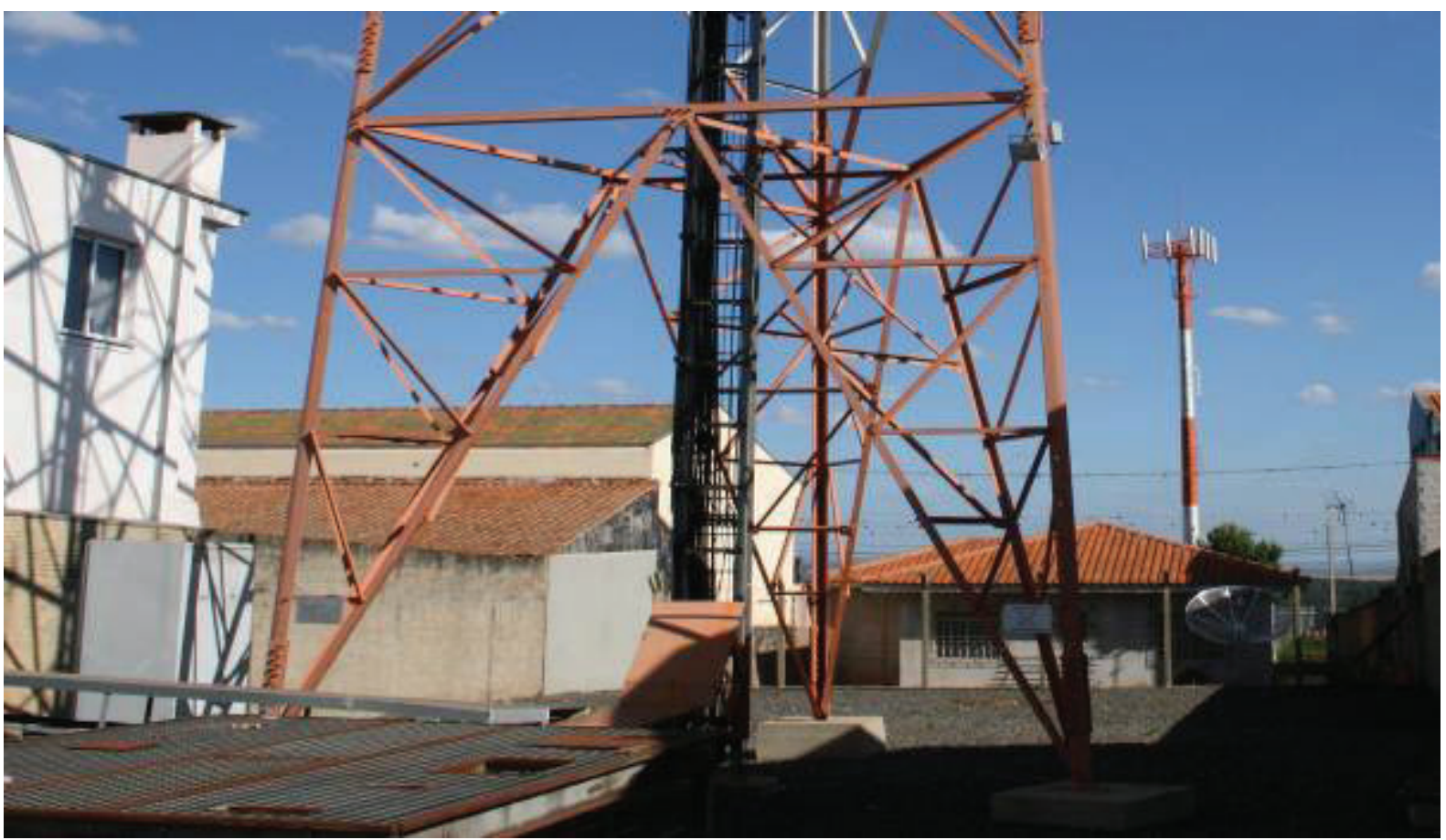

Figura 3 - Duas torres de uma concentração de três ERBs.

O fenômeno da concentração observado em Ponta Grossa é detectável facilmente em outras cidades, isto porque, esse fenômeno tem intíma relação com a topografia. Em cidades cercadas ou entremeadas por morros elevados, como por exemplo, as cidades de União da Vitória (PR), Balneário Camboriú (SC) e Rio de Janeiro (RJ), onde foram realizadas observações comparativas, há a constatação do fenômeno da concentração. Quando o fenômeno da concentração possui mais de duas torres instaladas, normalmente encontra-se a designação comparativa de "alfineteiro" para tal ocorrência. É bem verdade que, a concentração não significa automaticamente que essa aparência de alfineteiro ocorra. A configuração clássica, ou seja, a de alfineteiro, ocorre quando em uma superfície elevada (a ponta de um morro) estão cravados vários tipos de torres de telecomunicações, dentre elas, a de telefonia móvel. Para justificar mais o termo alfineteiro, as torres nesse morro estão muito próximas umas das outras, lembrando um conjunto de alfinetes instalados em um alfineteiro e, para completar, a topografia local acaba por lembrar esse utensílio de costura.

Em Ponta Grossa, por não existir morros elevados, a aparência de alfineteiro é menos clássica. Os morros são mais baixos e seus topos bem largos, permitindo um bom afastamento entre as torres que porventura lá sejam instaladas. Este registro foi efetuado dentro do perímetro urbano de Ponta Grossa (área abrangida pela pesquisa), onde os locais de concentração não se mostram densamente ocupados por torres. As distâncias entre as torres, nesses locais, atingem centenas de metros, não produzindo a aparência de alfineteiro e a quantidade de torres instaladas em uma mesma área não são grandes, sendo no máximo de três torres apenas.

Portanto, no caso de Ponta Grossa não ocorre, dentro do perímetro urbano, o fenômeno da concentração tipo alfineteiro (concentração clássica), mas sim, a concentração dispersa. Exemplo máximo é o que ocorre junto à Avenida Visconde de Mauá, que pode ser visto na figura 4, onde uma imagem de satélite indica as distâncias entre três torres.

\section{FENÔMENO DO ALINHAMENTO VISUAL}

Este fenômeno se instaura quando o observador pode perceber, a partir de determinadas posições, certos padrões geográficos das ERBs da telefonia móvel, ou seja, o fenômeno depende do ponto de observação e da perspectiva da cidade obtida daquele local. Assim, em um pequeno tre- 
cho da paisagem, podem ser observadas duas ou mais ERBs (exemplo na figura 2). Entretanto, tal fenômeno é reflexo de outros, como o do posicionamento de várias ERBs próximas a grandes vias de trânsito. Em alguns casos, ao se observar no sentido longitudinal de uma grande via de trânsito, pode-se visualizar uma concentração de ERBs em um trecho mais ou menos extenso da paisagem.

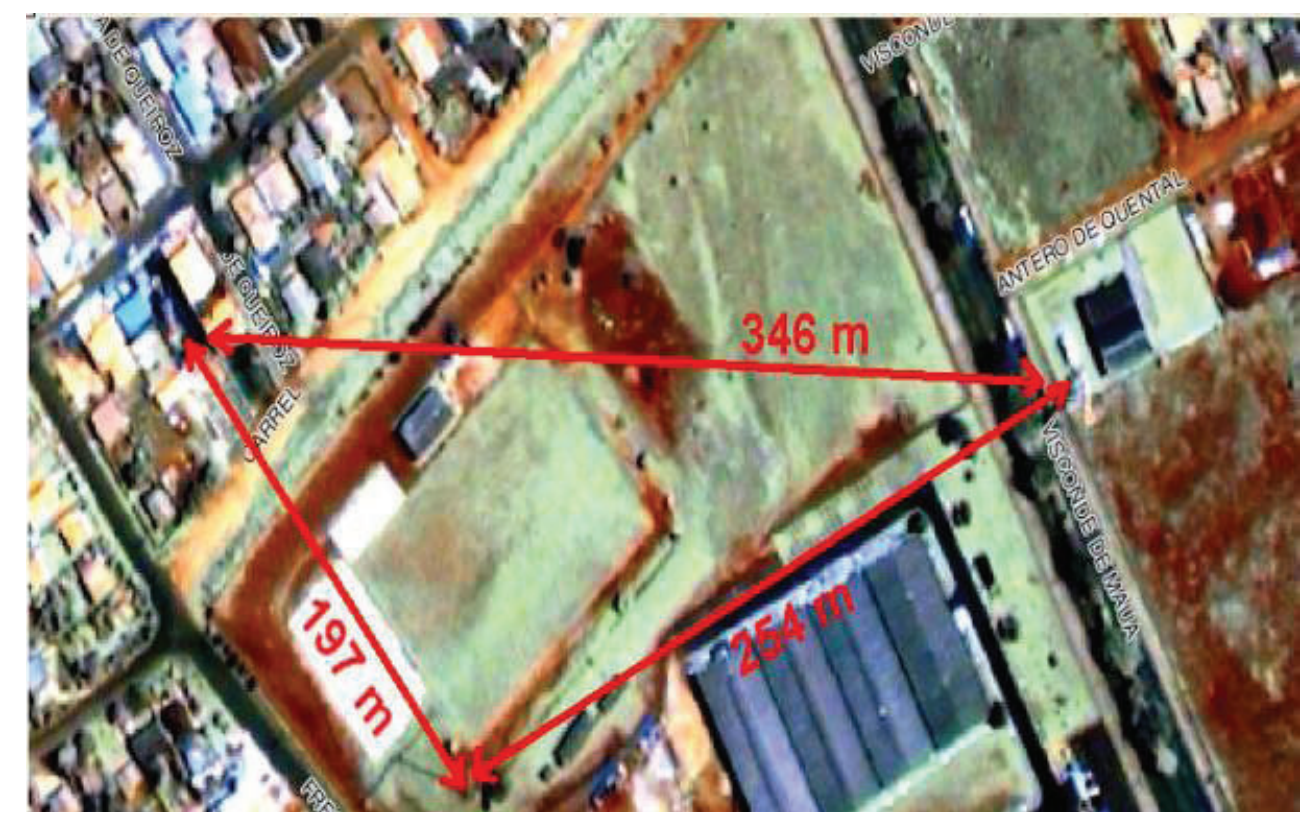

Figura 4 - Duas de um conjunto de três ERBs envolvidas em um fenômeno da concentração.

Indubitável é que, as vias de trânsito que se tornaram de grande fluxo atingiram esse grau de importância devido suas topografias mais suaves (vias que ligam o centro da cidade a bairros populosos e a saída que leva às mais importantes rodovias que conectam a cidade ao resto do país). A constatação do que parece um grupo de ERBs em série, seguindo uma linha tortuosa (o traçado da via de trânsito), associado ao relevo suave permite que, de certos pontos da cidade, seja observado um grupo de ERBs ocupando um pequeno trecho da paisagem urbana, sobrecarregando a vista com uma paisagem poluída com os elementos da telefonia móvel. Dois exemplos desse fenômeno observados em Ponta Grossa são representados pelas figuras 5 e 6.
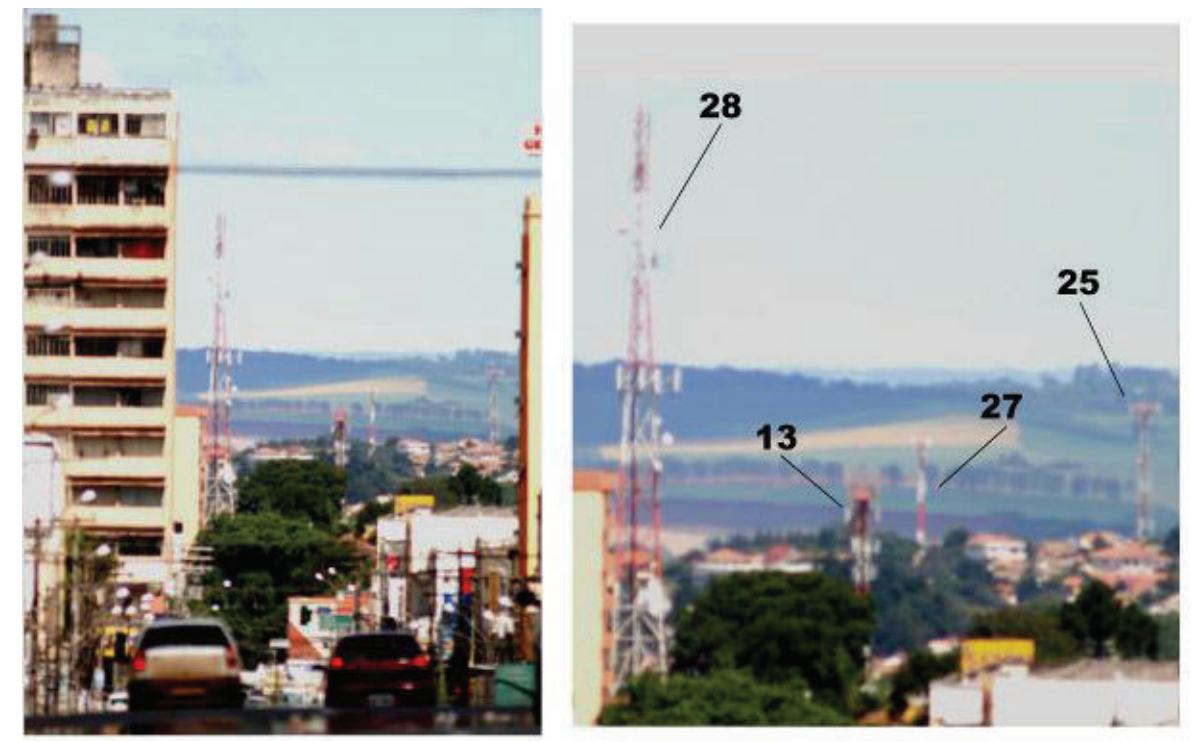

Figura 5 - Paisagem, da Avenida Balduíno Taques (Ponta Grossa, PR) em direção ao Sul, mostrando o fenômeno do alinhamento visual 


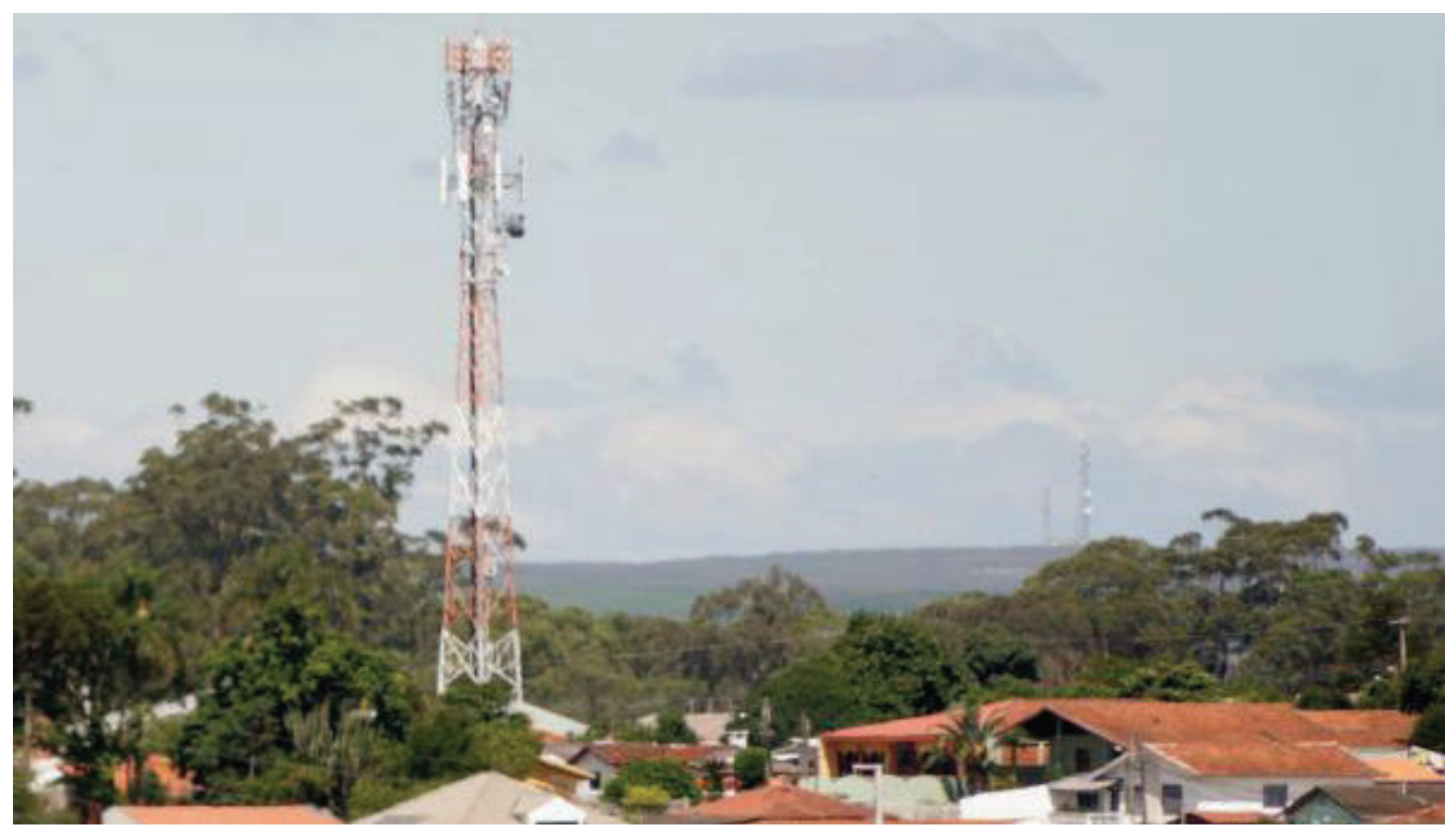

Figura 6 - Paisagem obtida a partir da Rua Penteado de Almeida (Bairro Centro de Ponta Grossa, PR) em direção ao leste, mostrando o fenômeno do alinhamento visual. Com uma torre mais próxima e duas à direita alinhadas a vários quilômetros de distância

\section{FENÔMENO DO COMPARTILHAMENTO}

O compartilhamento não surge naturalmente entre as empresas de telefonia móvel, mas por imposição das legislações criadas para controlar e evitar os abusos das mesmas. Foi lançada uma nova orientação refletindo-se sobre a paisagem urbana ao aprovar-se como lei o "Regulamento de compartilhamento de infraestrutura entre prestadoras de serviço de telecomunicações" (ANATEL, 2001), anexo da Resolução 274 de 05 de setembro de 2001, que se referia ao compartilhamento de infraestrutura entre os setores de energia elétrica, telecomunicações e petróleo. Este regulamento obriga que as empresas de telefonia, quando técnicamente seja permitido, compartilhem as torres entre si, sendo instalados equipamentos de duas ou mais empresas em uma mesma torre de sustentação. Tal lei objetiva evitar a poluição visual advinda da instalação desnecessária de várias torres em uma mesma região.

Na figura 08, é apresentado um interessante caso dessa classe de fenômeno com o compartilhamento de uma única torre por quatro empresas de telefonia, sendo visíveis em vários níveis as antenas instaladas por empresas diferentes. A comprovação prática disto pode ser vista na quantidade de armários ou vagões instalados ao redor da torre, bem como pela quantidade de postes do sistema de alimentação elétrica. Cada empresa tem seus próprios postes e armários (ou vagões), que não são compartilhados entre si. O compartilhamento ocorre não só com a torre, mas também com o terreno onde ficam instalados os elementos de solo.

\section{FENÔMENO DA SOBREPOSIÇÃO}

A sobreposição difere do fenômeno do compartilhamento por associar um elemento específico de uma atividade humana juntamente com outro, sobrepondo-se a este. Assim, soma-se ao elemento base mais uma característica e função, resultando em nova aparência das duas funções combinadas com reflexo na paisagem urbana. O fenômeno da sobreposição acontece puramente por motivos econômicos. 
Lembrando que a rentabilidade de um sistema de telefonia móvel é, atualmente, grande devido ao fato dos milhões de usuários que existem, as empresas deste setor ao analisarem uma cidade para a instalação ou simples ampliação de uma rede de telefonia, podem chegar à conclusão de que é mais vantajoso alugar um local pronto para a instalação de uma ERB do que investir em outro com apenas a infraestrutura básica presente (normalmente, possui somente o fornecimento de energia elétrica para o funcionamento da ERB). Assim, topos de edifícios, torres de igrejas, shoppings centers e outras construções que apresentem um posicionamento geográfico útil para uma rede de telefonia, bem como uma elevação considerável do solo, podem ser utilizados como pontos de instalações de ERBs.

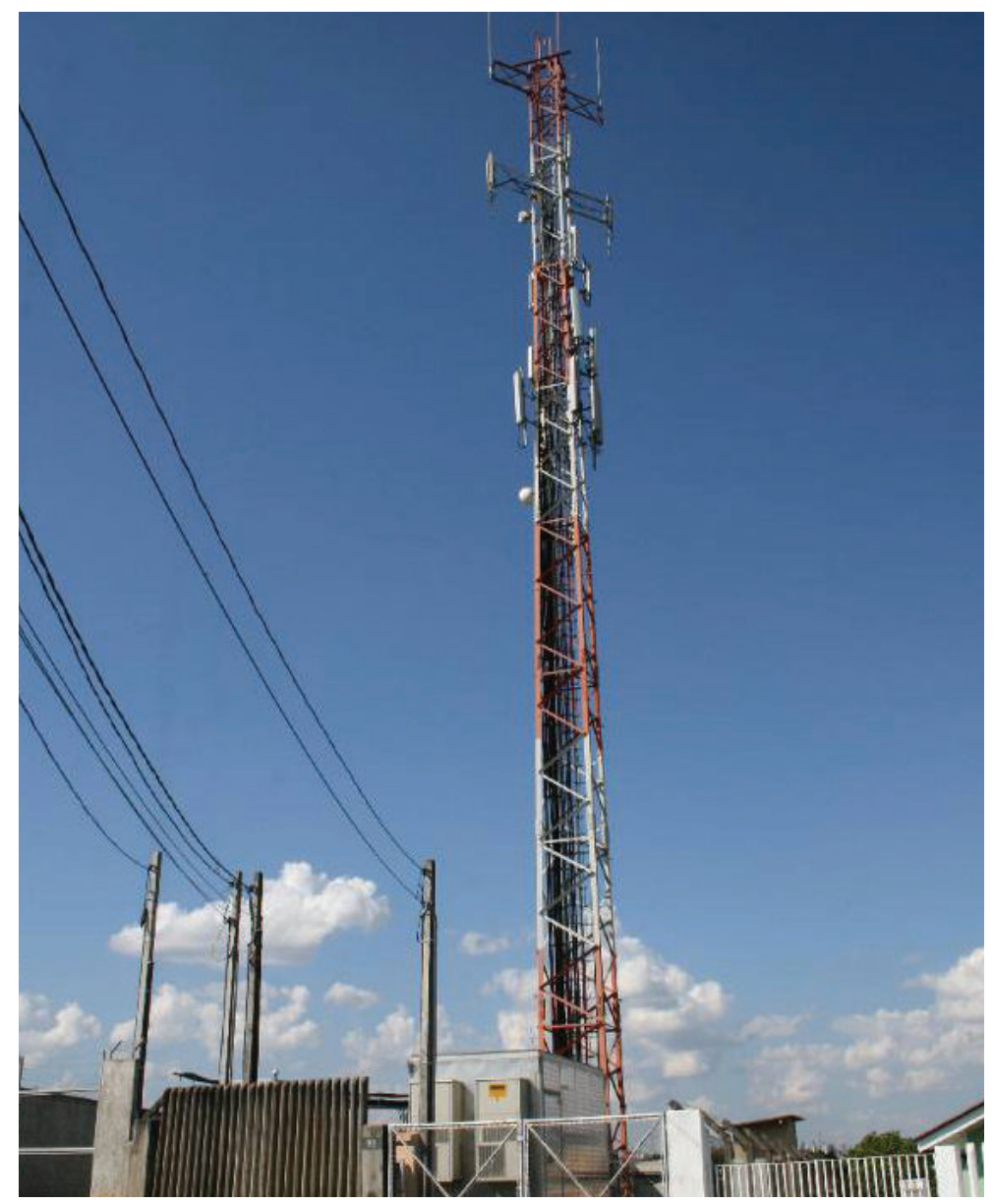

Figura 7 - ERB de telefonia móvel (objeto 24), compartilhada entre quatro empresas de telefonia, o que é comprovado pelos quatro postes de fornecimento de energia elétrica

Este fenômeno é aquele que faz com que uma ERB não seja instalada no solo, mas sim sobre um objeto urbano já existente, se sobrepondo a ele. Essa adição ao elemento já existente pode ser bem expoente, quando trata-se do setor da utilização comercial do rádio e da televisão. O fenômeno da sobreposição na telefonia celular é bem mais discreto, não adicionando elementos de grande monta. Dois exemplos são apresentados nas figuras 8 e 9.

O fenômeno da sobreposição é, juntamente com o do compartilhamento, aquele que reduz a poluição visual oriunda da instalação das ERBs de telefonia móvel. O compartilhamento evita a instalação de mais torres e a sobreposição evita a instalação de grandes torres. Na verdade há a instalação de uma pequena estrutura, algo como uma pequena torre (comumente com 5 metros de altura, contra as torres comuns de 30, 40, 50 ou 60 metros) sobre edificações já existentes, evitando o uso de um terreno para acolher uma grande torre. Entretanto, essa pequena ERB pode apresentar configurações diferentes conforme as necessidades de colocar mais ou menos antenas, exigindo uma estrutura maior ou menor. 


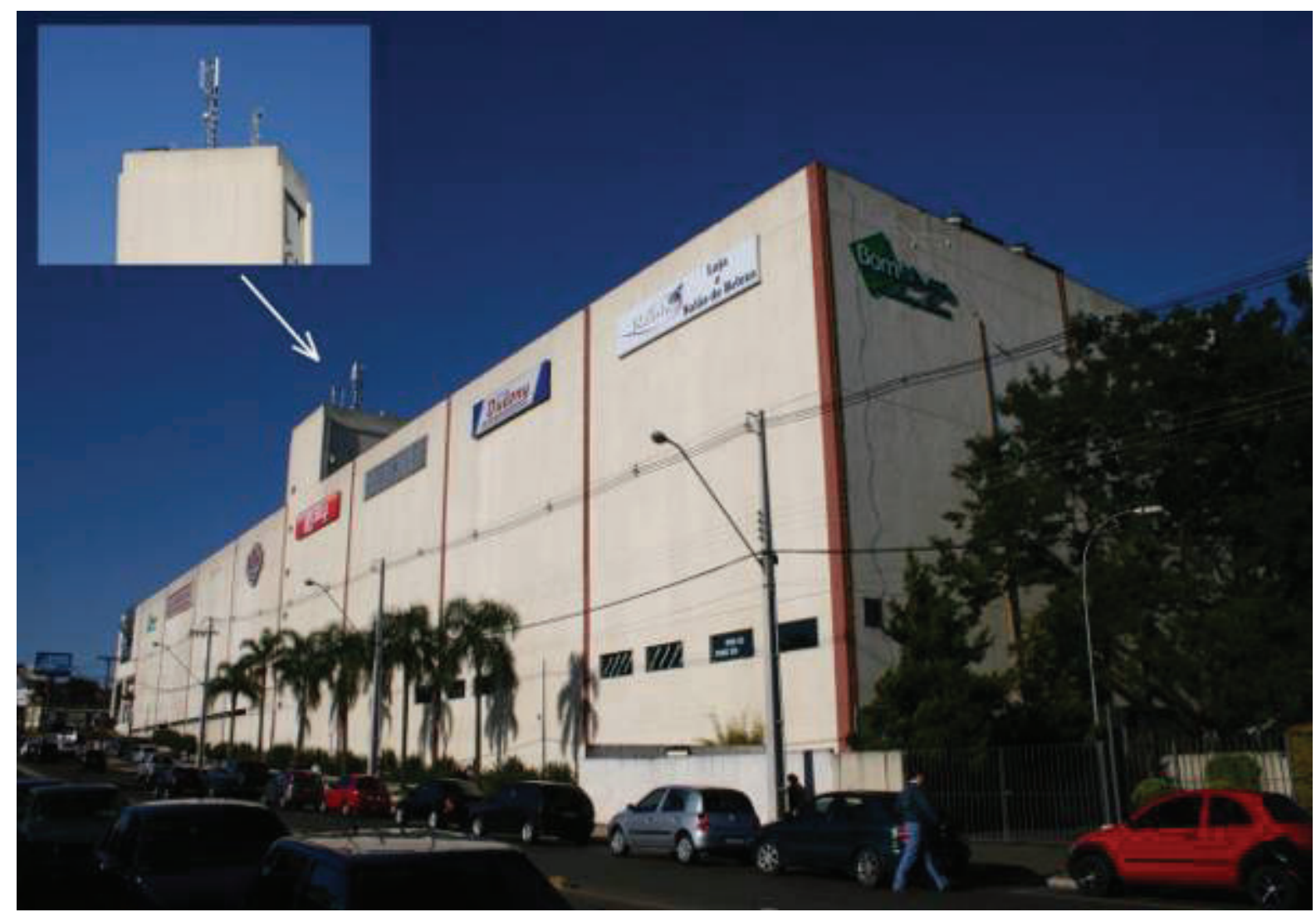

Figura 8 - Sobreposição de uma ERB sobre a caixa de água de um shopping center

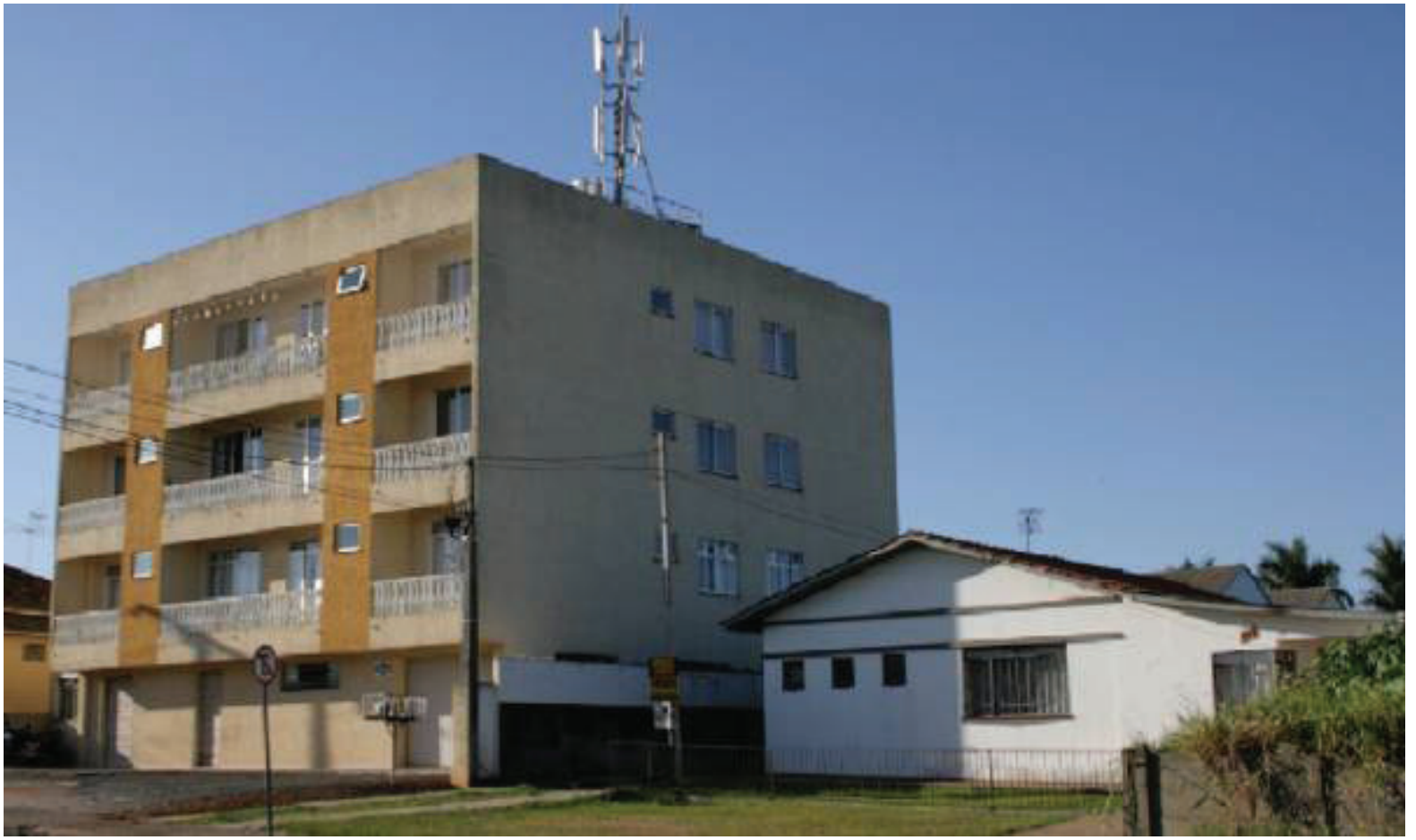

Figura 9 - Sobreposição de uma ERB sobre a caixa de água de um shopping center . 


\section{FENÔMENO DO BORDEAMENTO}

É sobremodo importante assinalar que não foi observada distinção por classe social na implementação de torres nas cidades. Grandes torres foram encontradas em frente a residências de alto padrão, como também ao lado de casas humildes. O posicionamento geográfico para fechar uma rede é o que importa e não o tipo ou classe social da região da instalação. Entretanto, certos bairros não apresentaram a presença de ERBs. Isto foi explicado pelo fenômeno do bordeamento, notado visualmente por uma visita aos bairros com essa característica.

Uma análise visual do local indicou imediatamente o porquê da aparente repulsão de ERBs nessas áreas. A explicação é totalmente técnica. Na montagem de uma rede de telefonia celular, a infraestrutura vai ser instalada no solo ou sobre construções pré-existentes, contudo, em ambos os casos deve ser considerado o meio físico entre dois pontos de instalação, onde cada ERB deve ter contato visual entre si (tecnicamente significa que os sinais emitidos pelas antenas não serão retidos por obstáculos no caminho).

O relevo da área urbana com suas elevações e baixios, morros, desníveis, arroios e trechos planos, oferecem aos planejadores o desafio de encaixar os pontos da rede em locais que permitam a interconexão entre os mesmos. Assim, torna-se possível se falar em forças de atração e repulsão para a instalação de pontos de uma rede de telefonia móvel, primeiramente pela sua posição em relação aos pontos já existentes mais próximos ao novo ponto da mesma.

As áreas mais baixas não permitem atingir muitos pontos da rede, visto que as ondas eletromagnéticas utilizadas na conexão entre os pontos viajam em linha reta e são detidos por obstáculos. Assim, alguns pontos mais elevados, sejam em terrenos ou em topos de edifícios, são atrativos para a instalação de ERBs, pois permitem uma linha de contato com outros pontos de uma rede. Por este motivo, vários terrenos mais elevados em relação ao resto da região, são procurados para receber uma ERB.

Entretanto, alguns locais aparentemente inadequados para a instalação de pontos de uma rede mostram-se úteis por estarem alinhados e em "contato visual" com outros pontos da rede. Exemplo disso são antenas instaladas na encosta de uma depressão, pois a encosta do outro lado fica totalmente desobstruída para o contato via ondas eletromagnéticas. Tecnicamente encontra-se o conceito de área de cobertura, que apresenta áreas de "sombra" podendo ser produzidas não só pelo meio físico (locais baixos, encostas de montanhas, etc.), mas também pela presença de construções diversas.

No caso dos bairros sem ERBs, nota-se uma topografia em declive que contempla as porções dos bairros adjacentes, onde estão instaladas EBRs em local elevado. Assim, quando se observa das partes mais baixas de um bairro sem ERB vê-se a distância, várias torres posicionadas na porção mais alta de outros bairros, dando acesso visual e, consequentemente, emitindo sinais de telefonia, totalmente desobstruído para o bairro sem ERB. Por isto, não há necessidade de ERBs em bairros que não as tenham, pois já estão servidos pelas ERBs dos bairros vizinhos.

Como remate é importante dizer que se há contato visual, também há contato de rádio, visto que as distâncias das torres ao bairro estão dentro do alcance das emissões das mesmas (07 quilômetros aproximadamente). No bairro Santa Paula da cidade de Ponta Grossa (PR), não foi necessária a instalação de ERBs pela falta de obstáculos naturais e artificiais entre as antenas existentes na borda do bairro e os usuários do local em questão. Assim, Santa Paula se beneficia com as ERBs já instaladas fora de seu território, ficando livre de suas presenças.

\section{CONSIDERAÇÕES FINAIS}

Não se pode olvidar que as ERBs geram fenômenos sobre a paisagem. Alguns evitam novas inclusões de ERBs (fenômeno do compartilhamento e bordeamento) e outros criam novas feições (fenômenos da concentração, alinhamento visual, sobreposição e bordeamento). 
O supramencionado se reflete na forma de sentir a cidade, de um lado, ao ignorar a influência da presença das ERBs (onde não estão presentes ou então, existem em pequena quantidade), de outro lado, a transmitir sensação de saturação e de presença exagerada desses objetos urbanos, posto ocorrer uma concentração ou alinhamento no campo de visão. Como resultado, a paisagem vista de certos locais da cidade fica carregada com elementos que colocam sua aparência em destaque. No caso das torres de telefonia, essa aparência não segue a estética, mas somente a técnica, ou seja, a função.

\section{REFERÊNCIA BIBLIOGRÁFICA}

BRASIL. Anexo da Resolução 274 de 05 de setembro de 2001: Regulamento de compartilhamento de infra-estrutura entre prestadoras de serviços de telecomunicações. Disponível na internet em: http://www. anatel.gov.br/Portal/exibirPortalInternet.do\# . Acessado em 12 de setembro de 2008.

CARLOS, A. F. A. (org). Novos caminhos da Geografia. São Paulo: Contexto, 1994.

CASTRO, I. E., GOMES, P.C. da Costa, CORREAA, R. L. Geografia: Conceitos e Temas. Rio de Janeiro: Bertrand Brasil, 1995.

HARVEY, David. Condição pós-moderna. São Paulo: Edições Loyola, 2005.

KACZMARECH, Maurício José. Redes Técnicas: o caso da infraestrutura da telefonia móvel em Ponta Grossa - PR. 2009. Dissertação (Mestrado em Geografia) - Universidade Estadual de Ponta Grossa, Ponta Grossa, 2009.

MÁZ, Juliano. Abaixo a poluição visual. Veja. São Paulo, edição 1745, ano 35, nº 13, p.27, 3 de abril de 2002 MOPU, Carlos. El paisage: Unidades temáticas ambientales de La directijo generale del medio ambiente. Madrid: Ministério de Obras Públicas y Urbanismo. 1987. 107p.

Ribeirão Preto. Anteprojeto de Lei do Mobiliário Urbano de Ribeirão Preto, 1999, Prefeitura Municipal de Ribeirão Preto.

SANCHEZ, Joan - Eugeni. Espacio, Economia y Sociedad. Madrid: Siglo Veintiuno de Espanha Editores S.A.

SANTOS, Milton. A natureza do espaço. São Paulo: Hucitec, 2003.

SANTOS, Milton. Espaço \& Método. São Paulo, 2001, Ed. Nobel.

SANTOS, M. Metamorfoses do espaço habitado. São Paulo: Hucitec. 1988.

SANTOS, M. Pensando o espaço do Homem. São Paulo: Hucitec. 1986.

TOFETI, Alexandre Resende. A interferência das torres de telefonia celular no território das regiões metropolitanas. 136 p., UNB-GEA, Gestão Ambiental e Territorial, 2007. Dissertação de Mestrado - Universidade de Brasília. Departamento de Geografia.

VILAGRASA, Joan. Estudio de la Morfologia urbana: uma aproximación. Disponível na internet. Em $<$ http://www.ub.es/geocrrit/menu.htm>. Acessado em 13 Set 2003

Trabalho enviado em maio de 2011

Trabalho aceito em julho de 2011 